\title{
Information Behaviors and Information Literacy Skills of LIS Students: An International Perspective
}

\author{
Laura Saunders
}

School of Library and Information Science, Simmons College, Email: laura.saunders@simmons.edu

Serap Kurbanoglu

Department of Information Management, Hacettepe University, Email: kurbanogluserap@gmail.com

Joumana Boustany

Department of Information Communication, Université Paris Descartes, Email: jboustany@gmail.com

Guleda Dogan

Department of Information Management, Hacettepe University, Email: guledaduzyol@gmail.com

\section{Peter Becker}

The Hague University of Applied Sciences, the Netherlands, Email: p.g.becker@hhs.nl

\section{Eliane Blumer}

Department of Information Science, Haute Ecole de Gestion, Email: eliane.blumer@hesge.ch

\section{Sudatta Chowdhury}

Department of Computer \& Information Sciences, University of Strathclyde,

Email:sudatta@hotmail.co.uk

\section{Milena Dobreva}

Library Information and Archive Sciences Department, Malta University,

Email: milena.dobreva@gmail.com

\section{Natalia Gendina}

Scientific and Research Institute of Information Technologies, Kemerovo State University of Culture and Arts Kemerrovo, Email: gendina@inbox.ru

\section{Ivana Hebrang Grgic}

Department of Information and Communication Sciences, Faculty of Humanities and Social Sciences, University of Zagreb, Email: ihgrgic@ffzg.hr

\section{Gaby Haddow}

Department of Information Studies, Curtin University, Email: G.Haddow@curtin.edu.au

\section{Tibor Koltay}

Department of Information and Library Studies, Szent István University,

Email: koltay.tibor@abk.szie.hu

\section{Terttu Kortelainen}

Department of Information Studies, Oulu University, Email: terttu.kortelainen@oulu.fi

\section{Monika Krakowska}

Department of Management and Social Communication Institute of Library and Information Science, Jagiellonian University, Email: monika.krakowska@uj.edu.pl

\section{Shaheen Majid}

Division of Information Studies, Wee Kim Wee School of Communication \& Information, Nanyang Technological University, Email: ASMAJID@ntu.edu.sg 


\section{Marina Mezhova}

Scientific and Research Institute of Information Technologies in Kemerovo State University of Culture and Arts Kemerrovo, Email: mezhova75@mail.ru

\section{Angela Repanovici}

Transilvania University of Brasov, Email: arepanovici@gmail.com

\section{Jurgita Rudžioniene}

Faculty of Communication Institute of Library and Information Science, Vilnius University, Email: jurgita.rudzioniene@kf.vu.lt

\section{Rene Schneider}

Department of Information Science, Haute Ecole de Gestion, Email: rene.schneider@hesge.ch

\section{Ana Lucia Terra}

Information Science Department, Superior School of Industrial Studies and Management, Polytechnic Institute of Porto, Email: analuciaterra@yahoo.com

\section{Tania Y. Todorova}

State University of Library Studies and Information Technologies, Email: dr.tanya.todorova@gmail.com

Librarians are expected to be expert searchers, and developing information literacy skills to navigate the vast world of information is a focus of most library and information science (LIS) programs. It is important to understand the information literacy and behaviors of LIS students to see if they are employing the skills they will need to assist and educate their future patrons, yet there is relatively little research into the information literacy and behaviors of librarians and library students. Using a survey on information behaviors, this study addresses this gap in the literature by examining how LIS students in 18 countries search for, evaluate, and use information in various contexts, and on whom they rely for help. The results of this study demonstrate library science students' information literacy skills within an international context. Faculty in LIS programs will be interested to see how their students approach information problems, and might use this understanding to develop or strengthen courses and inform curricular decisions.

$\mathbf{L}$ ibrarians are expected to be expert searchers of all kinds of information in all formats. Developing the knowledge and skills to navigate the vast world of online and print information is typically a focus of most library and information science (LIS) programs. Understanding information literacy levels and how students approach information seeking tasks can inform curricular decisions. As Chung and Neuman note, "because learning is the primary goal of students' information seeking and use, how students' information seeking and use contributes to learning should be studied in various contexts ... [and] with different learning tasks" (2007, p. 1516). Thus it is important to un- derstand the information literacy and behaviors of LIS students as a group to see if they are employing the skills they will need to assist and educate their future patrons.

On the other hand, it is not advisable to study LIS students as though they are a homogenous group, thereby ignoring possible differences of library and information science curricula as well as culture on information behaviors. In a systematic review of the literature on informationseeking behaviors of graduate students, Catalano (2013) noted some cultural differences in the information-seeking behaviors of international students studying in the United States. As the economy becomes increasingly globalized and as more 
librarians and library students choose to go abroad to study or work, it will be useful for librarians and LIS faculty to recognize these differences.

While there is a rich literature on information literacy and behaviors in general, there is relatively little research into the information literacy and behaviors of librarians and library students. Further, while some studies have focused on specific geographic areas, including Uganda (OkelloObura \& Ikoja-Odongo, 2010), Greece (Korobili, Malliari, \& Zapounidou, 2011), and Ireland (O'Farrell \& Bates, 2009), there are no studies that compare information literacy and behaviors of LIS students across different countries. Through a survey of the information literacy skills and information problem-solving habits of LIS students in 18 countries, the authors of this study begin to address this gap in the literature. The study investigates how LIS students search for, evaluate, and use information in various contexts, and on whom they rely for help.

The results of this study demonstrate the current state of library science students' information literacy skills and information problem-solving habits within an international context. Faculty in LIS programs will be interested to see how their students approach information problems especially as they teach greater numbers of international students or consider collaborating with international colleagues. Librarians might be interested to see how current library students in various countries approach information tasks, and how well they are being prepared to serve as intermediaries and instructors in a complex information environment. In addition, an international understanding is important for students and professionals to compete in a global job market.

\section{Literature Review}

The body of literature on information literacy and behaviors is extensive and will not be reviewed at length here. The- ories of Information Behavior, edited by Fisher, Erdelez, and McKechnie (2005), offers over 70 chapters, each outlining a theory, model, or conceptual framework related to information-seeking and information behaviors, such as Kuhlthau's Information Search Process (ISP) model of affective behaviors of information seeking, Dervin's theory of Sense-Making, and Bates' berrypicking model. The Pew Research Center's Internet and American Life Project has issued a number of reports that probe the online searching behaviors of the American adult population, showing that the vast majority of American adults use the Internet to search for information, and that they are generally confident in their search skills and happy with the results they get (see, e.g., Estabrook, Witt, \& Rainie, 2007; Fox, 2010; Purcell, Brenner, $\&$ Rainie, 2012). The OCLC Perceptions of Libraries, 2010: Context and Communities (2010) similarly explored library usage of adults and college students. The European Council on Information Literacy (ECIL, http://www.ilconf.org/) runs an annual conference with contributed papers that examine information literacy and information behaviors in a wide variety of contexts. The Project Information Literacy (PIL) has been conducting longitudinal studies of college students' information literacy and behaviors since 2008, and has compiled a clearinghouse of reports, videos, and other publications on their findings (see e.g., http://projectinfolit.org; Head, 2007; Head \& Eisenberg, 2009). The Project on Information Literacy's work has established college students' frustration with context-gathering and their preference for resources that are familiar and have given them good results in the past. Catalano (2013) offers a comprehensive review of the literature on graduate students' information-seeking behaviors. Other studies have established the importance of convenience in terms of ease of access and use for online searchers (Connaway, Lanclos, \& Hood, 2013; Connaway, Dickey, \& Radford, 2011). 


\section{Librarian and Library Student Information Behavior}

A handful of studies have focused on information-seeking or information literacy competencies among librarians in relation to their professional activities. Brown and Ortega (2005) found that physical science librarians rely most heavily on personal communications and listservs in order to stay current in their field, followed by scholarly journals, web sites, conferences, and trade and professional magazines. Liaison librarians need detailed knowledge of subject resources, as well as excellent skills in information discovery and literature searching in order to support faculty research (Brewerton, 2012). Tan, Gorman, and Singh (2012) found that, although most school librarians in Malaysia were familiar with information literacy concepts, they were not comfortable with their own information literacy abilities. Most self-reported their information literacy skills as being "average" to "poor." It is important to note, however, that not all of the respondents in their sample had formal training as librarians.

Studies of library science students reveal a range of behaviors, some of which are similar to those of the general population. LIS students tend to favor online resources (Campello \& Abreu, 2005; de Jong \& Branch 2006; O'Farrell \& Bates, 2009; Tracy \& Searing, 2014), and they consult a wide range of resources (Campello \& Abrue, 2005; Tracy \& Searing, 2014). While LIS students report high self-efficacy and competence with computers, they are generally more comfortable using the computer to communicate or to conduct research for personal rather than academic purposes (Malliari, Korobili, \& Togia, 2012), and some report a need for greater exposure to and training in the use of online resources (Okello-Obura \& Ikoja-Odongo, 2010).

De Jong and Branch (2006) found that students in an online library teacher program tended to rely on sources with which they were already familiar, and favored those with online full-text access. Further, those students seemed to be unaware of many of the library services offered by their program, and turned instead to local public libraries for resources. LIS students tend to consult with reference librarians only occasionally (Campello \& Abreu, 2005; Tracy \& Searing, 2014), with those in an undergraduate LIS program in Brazil relying most heavily on professors and classmates for advice (Campello \& Abreu, 2005).

Results of a research study on LIS students' perceived self-efficacy for information literacy in Turkey indicates that students feel confident about performing information literacy related tasks and that their levels of self-efficacy increases slightly over time (Kurbanoglu, 2003). However, Conway (2011) found that both undergraduate and post-graduate LIS students in Australia have problems with basic information literacy skills, with students averaging a score of $73 \%$ on a survey test. Undergraduates in particular scored poorly on questions related to defining and articulating an information need and understanding the purpose, scope and appropriateness of a variety of information sources. Undergraduate LIS students in Brazil similarly found the initial stages of research, such as choosing and limiting a topic, to be difficult and expressed negative feelings at that stage (Campello $\&$ Abreu, 2005). The lack of information literacy skills displayed by LIS students prompted Campello and Abreu to conclude that "future librarians are not sufficiently prepared to perform the kind of search tasks for which they will be expected to act as mediators for others in the process of learning from information" (p. 49).

\section{Methodology}

The purpose of this study is to investigate the information literacy skills and behaviors of LIS students across different countries, both to explore those skills and 
behaviors generally, and to examine the extent of differences in those skills and behaviors. In particular, this study examines the following questions:

What strategies and sources do LIS students employ when gathering information for course-related information needs?

Are there differences in the information seeking behaviors of LIS students in different countries?

The project was initiated and organized by two of the study authors, who recruited LIS professionals and faculty from around the world. Ultimately, 21 researchers from 18 countries participated. Because of the scope of the project, it was determined to use a web survey for data collection. Due to its quantitative nature, and the ability to administer it remotely and online, a survey would allow for a larger sample and greater ease of analysis. A single survey could also be easily translated to different languages and hosted on one site to facilitate the data collection.

One of the organizing authors gained permission from Alison Head to use the PIL survey (available at http://projectinfolit.org/images/pdfs/pil_fall2010_survey_fullreport1.pdf) as the data collection instrument. This survey was chosen for several reasons. As the core instrument for PIL, this survey has the benefit of having been widely used and tested through a series of PIL studies, and therefore is a valid instrument. With its focus on questions of student information behaviors, including where they start their research, what sources they consult, and how they evaluate their sources, the survey was well suited to the research questions for this study. Finally, the data from the previous PIL studies conducted using this survey also offer a baseline of college undergraduate information literacy and behaviors with which the results of this study could be compared. The original PIL survey consists of two parts, one focusing on information behaviors related to everyday information needs, and one centered on information behaviors for course-related assignments. Because this study is concerned with the preparation of LIS students for professional roles, the researchers omitted the section on everyday life information and chose to study only students' behaviors related to course assignments.

Each researcher translated the original study into their own language, in order to allow survey participants to respond in their native language. Researchers made every effort to keep the meaning and intent of the original survey. Changes to the original questions were kept to a minimum and made only when absolutely necessary. Data collection took place in the fall of 2012 and spring of 2013. The researchers distributed the survey to the population of LIS students in their respective schools, with most using some type of internal electronic communication.

\section{Limitations}

Like the PIL research on which it is based, this study relies on the perceptions and self-reported behaviors of students. While the survey questions themselves have been widely tested and used, any self-reported data raises questions of reliability and validity. Either intentionally or unintentionally, students might not accurately reflect their information behaviors in their answers. Students might not recall their behaviors clearly, or they might choose answers that they believe are the "correct" answers regardless of whether those answers really describe their own actions. For instance, students could under-report use of resources like Google or Wikipedia because they believe they are not supposed to use them. Further research could supplement this study by using methods such as thinkaloud protocol or diaries to better capture students' actual behavior.

In addition, while this study is international in scope, the majority of the 
participating countries are concentrated in Europe. Coordinators of the study relied on personal knowledge and referrals to recruit colleagues to participate in the research, which partly accounts for the somewhat limited geographic scope. Further, participants had to commit to a predetermined timeline for completing data collection. Some researchers were interested in participating but were unable to meet the timeframe and therefore were not included in the findings reported here. Thus, it must be acknowledged that the results of the study might reflect particular similarities or differences of the participating countries.

\section{Findings}

The purpose of this study is to explore how LIS students from 18 countries approach course-related information tasks. The survey asked students about the kinds of assignments they receive, the sources that they consult, and their approaches to evaluating information. The survey also included questions about research habits, attitudes, and use of productivity tools. The following sections detail the aggregate findings of this study and a cross-country analysis, beginning with an overview of the data collection and response rates.

\section{Demographics}

As noted above, data was collected in 18 different countries, and ultimately a total of 1249 responses were received. In some countries, the bachelor's degree is the minimum needed to practice as a professional librarian, while in others the master's is the terminal degree. As such, the survey respondents included a mix of students at both the bachelor's and master's levels, depending on the country. Researchers distributed the survey to the total population of students at their respective institutions, using a variety of distribution methods. Turkey had the largest number of respondents $(n=210)$, and the United
Kingdom had the lowest number $(n=6)$. Response rates varied from a low of about $10 \%$ in Australia and the Netherlands to a high of $92 \%$ in Lithuania. Table 1 shows the survey distribution method, degree level of the students surveyed, total number of respondents, and response rate by country.

The United States used a different age scale from the rest of the participants, so the following age breakdown is for the eighteen countries, minus the United States. The majority of respondents were between the ages of 18 and 23 (63\%). Only 10\% of respondents were over the age of 35 , and just seven respondents $(0.6 \%)$ were under the age of 18. Ages of participants in the United States skewed slightly older, with $65 \%$ of respondents between the ages of 22 and 30. Further, 13\% of United States respondents were over the age of 40 , while only $3 \%$ were under the age of 21 . Women dominated the survey across countries, with $80 \%$ of respondents indicating they were female.

\section{Starting Course-related Assignments and Searching for Resources}

Students were asked about the perceived level of difficulty for 13 tasks related to starting a course assignment and searching for resources for that assignment. According to the responses, LIS students generally find the pre-research work to be more difficult than the tasks related to finding and evaluating resources. For instance, $65 \%$ of respondents either disagreed or strongly disagreed that finding sources in the library is difficult. Likewise, $76 \%$ disagree or strongly disagree that finding resources on the Web is difficult, and $52 \%$ disagreed or strongly disagreed that finding articles in library databases is difficult. Further 54\% disagreed or strongly disagreed that coming up with search terms is difficult. Just under half (46\%) disagreed or strongly disagreed that determining whether Web sites are credible is difficult. On the other hand, students were 
Table 1. Survey Distribution and Response Rate by Country.

\begin{tabular}{lcccc}
\hline Country & $\begin{array}{c}\text { Students } \\
\text { Level }\end{array}$ & Distributed via & $\begin{array}{c}\text { Total Number of } \\
\text { Respondents }\end{array}$ & $\begin{array}{c}\text { Estimated Response } \\
\text { Rate }\end{array}$ \\
\hline Australia & BA & $\begin{array}{c}\text { department mailing list and } \\
\text { e-learning platform }\end{array}$ & 51 & $10 \%$ \\
\hline Bulgaria & BA & e-mail & 94 & $60 \%$ \\
\hline Croatia & BA \& MA & e-learning platform & 110 & $40 \%$ \\
\hline Finland & BA \& MA & student listserv & 17 & $18 \%$ \\
\hline France & BA & in the classroom & 113 & $85 \%$ \\
\hline Hungary & BA & internal communication channel & 35 & $78 \%$ \\
\hline Lithuania & BA & printed version & 86 & $92 \%$ \\
\hline Malta & BA & email & 9 & $82 \%$ \\
\hline Netherlands & BA & - & 10 & $10 \%$ \\
\hline Poland & BA \& MA & e-learning platform & 176 & $85 \%$ \\
\hline Portugal & BA & e-learning platform & 66 & $74 \%$ \\
\hline Romania & BA \& MA & student listserv & 13 & $50 \%$ \\
\hline Russia & BA & e-mail & 29 & $50 \%$ \\
\hline Singapore & MSc & e-mail & 75 & $45 \%$ \\
\hline Switzerland & BA & mailing list & 53 & $17 \%$ \\
\hline Turkey & BA & internal communication channel & 210 & $80 \%$ \\
\hline UK & BA & internal communication channel & 6 & $20 \%$ \\
\hline USA & MA & student listserv & 96 & $17 \%$ \\
\hline
\end{tabular}

less confident about the early phases of an assignment. For instance, 56\% agreed or strongly agreed that getting started on an assignment is difficult. Similarly $46 \%$ and $45 \%$ respectively agreed or strongly agreed that defining a topic and narrowing down a topic for an assignment is difficult. Figure 1 shows the aggregate responses across all countries for the students' perceived level of difficulty with each task.

While these statistics describe the behaviors of LIS students generally, a chisquare test revealed correlations across countries for each of the 13 tasks ( $p=$ 0.000 for each of the 13 responses $)^{1}$. In

\footnotetext{
${ }^{1}$ Due to the variable response and participation rates, Finland, Hungary, Malta, the Netherlands, Romania, Russia, and the UK had to be eliminated from the cross-country analysis. Thus, the results reported for each chi-square test describe differences for students in Australia, Bulgaria, Croatia, France, Lithuania, Poland, Portugal, Singapore, Switzerland, Turkey, and the United States.
}

other words, LIS students rated the difficulty of each task differently depending on their home country. For instance, defining a topic appears to be most difficult for students in Portugal, Turkey and Singapore (more than $50 \%$ in each country either "agree" or "strongly agree"). Students in Turkey also appear to find determining the credibility of a web site more difficult than students from other countries did (58\%). Having to sort through irrelevant results to find what is needed is rated as difficult more often in Turkey (71\%) and Bulgaria $(65 \%)$. Narrowing down a topic is rated most difficult by students in France (61\%), Turkey (56\%), and Singapore $(52 \%)$, while students in France $(52 \%)$ and Lithuania (49\%) report that deciding which database to use is difficult at higher rates than students from other countries. It is interesting to note that students in Swit- 
zerland and the United States rated almost all of the 13 tasks as less difficult than students from other countries. Appendix A shows the percentage of respondents either agreeing or strongly agreeing with each statement by country.

\section{Preparing Course-related Assignments}

Another question asked respondents to rate the difficulty of tasks related to the mechanics of compiling research and completing assignments. Responses to this question were more mixed. There were not any tasks in this list that stood out as being particularly difficult for all or most students. Indeed, most students indicated that reading through the material, taking notes, integrating different sources, and knowing when to cite a source is not difficult. Overall, the most difficult aspects of the assignments appear to be rephrasing something that is already well expressed, and knowing whether the student has done a good job, with $47 \%$ and $45 \%$ respectively agreeing or strongly agreeing that these tasks are difficult. Appendix B shows the response rates for students across all countries for this question.

As with initiating an assignment and searching for resources, chi-square tests showed a correlation $(p=0.000)$ across countries for all responses to this question, except for the response "evaluating the sources I've found is difficult." Students in France expressed relatively more difficulty with deciding whether "the work is done" or not (73\% strongly agreed or agreed) and knowing whether use of a source constitutes plagiarism (over $57 \%$ ). Similarly, students in Turkey $(46 \%)$ and Portugal (42\%) were most likely to agree that knowing when to cite a source is difficult. Students in the United States expressed the least difficulty with knowing whether use of a source constitutes plagiarism $(13 \%)$, but were somewhat more likely than students in Switzerland to agree that knowing when to cite a source is difficult (12\% and $9 \%$ respectively). Students in Portugal found rephrasing what is already well expressed in a source more difficult than students from other countries (65\%). Students in the United States expressed the least

Having to sort through all the irrelevant results I get to find what I need is
difficult
Finding "gray literature" (e.g., thesis, reports, unpublished papers, etc.) is
difficult
Finding up-to-date materials is difficult
Figuring out where to find sources in the library is difficult
Determining whether a Web Site is credible or not is difficult
Finding sources to use "out on the Web" is difficult (e.g., Google,
Wikipedia, government sites)
Finding articles in the library's databases is difficult (e.g., LISA, WOS,
EBSCO, JSTOR)
Deciding which database to use is difficult
Building up the search strategy is difficult
Coming up with search terms is difficult
Narrowing down a topic is difficult


$\begin{array}{lllllllllll}0 & 10 & 20 & 30 & 40 & 50 & 60 & 70 & 80 & 90 & 100\end{array}$

$\square$ Strongly Agree $₫$ Agree $\backsim$ Neither Agree nor Disagree $\backsim$ Disagree $\backsim$ Strongly Disagree $\backsim$ No Experience with this Situation

Figure 1. Perceived Difficulty with Course-Related Assignments, Aggregate Responses. 


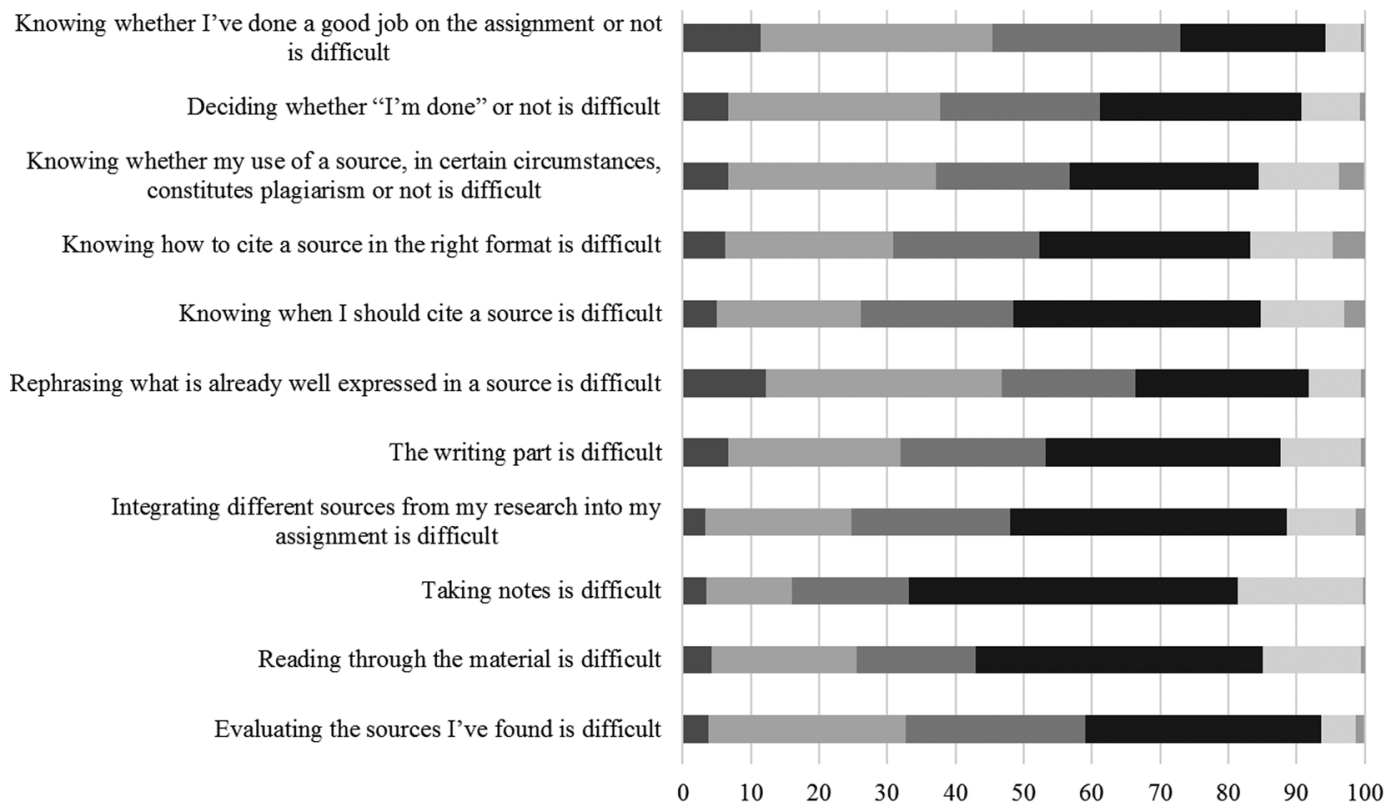

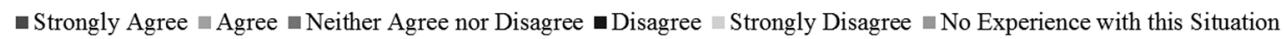

Figure 2. Perceived Level of Difficulty in Preparing Course-Related Assignments.

difficulty with evaluating sources $(9 \%)$, while students in Turkey (45\%), Portugal (44\%), and Lithuania (41\%) expressed the most difficulty. Figure 4 shows the rate at which respondents either strongly agreed or agreed with each statement by country.

\section{Consulting People and Resources}

Two questions asked students to rate the frequency with which they consult different resources or people for assistance when completing assignments, ranging from search engines and social networking sites to library databases, gray literature, instructors, classmates, and librarians. Search engines are the most widely consulted resources, with $86 \%$ of students indicating that they "almost always" or "often" use them. Search engines are followed by course readings $(70 \%)$, library catalogs $(56 \%)$, Wikipedia (54\%), and library shelves $(51 \%)$. LIS students are less likely to use social networking sites, slide sharing sites, video sharing sites, blogs, online forums and gray literature when doing assignments. Research databases fell to the middle, with $43 \%$ of students "almost always" or "often" using them for assignments. Figure 5 depicts the frequency with which students report using resources for assignments. Students rely mostly on classmates and instructors for support with assignments, with 70\% turning to classmates "almost always" or "often," and 54\% consulting with professors. Librarians are the last resource for most students with only $27 \%$ "almost always" or "often" meeting with librarians, while $16 \%$ report never meeting with a librarian. Figure 6 shows the rate at which students consult with particular people about assignments.

As with previous questions, the frequency with which LIS students consult various resources for course-related assignments showed some variance by country. A chi-square test showed a correlation for each of the fourteen resources by country $(p<0.05)$. Consulting library shelves is most common in Croatia (75\% almost always or often consult library shelves) and Poland (69\%), while students in the 


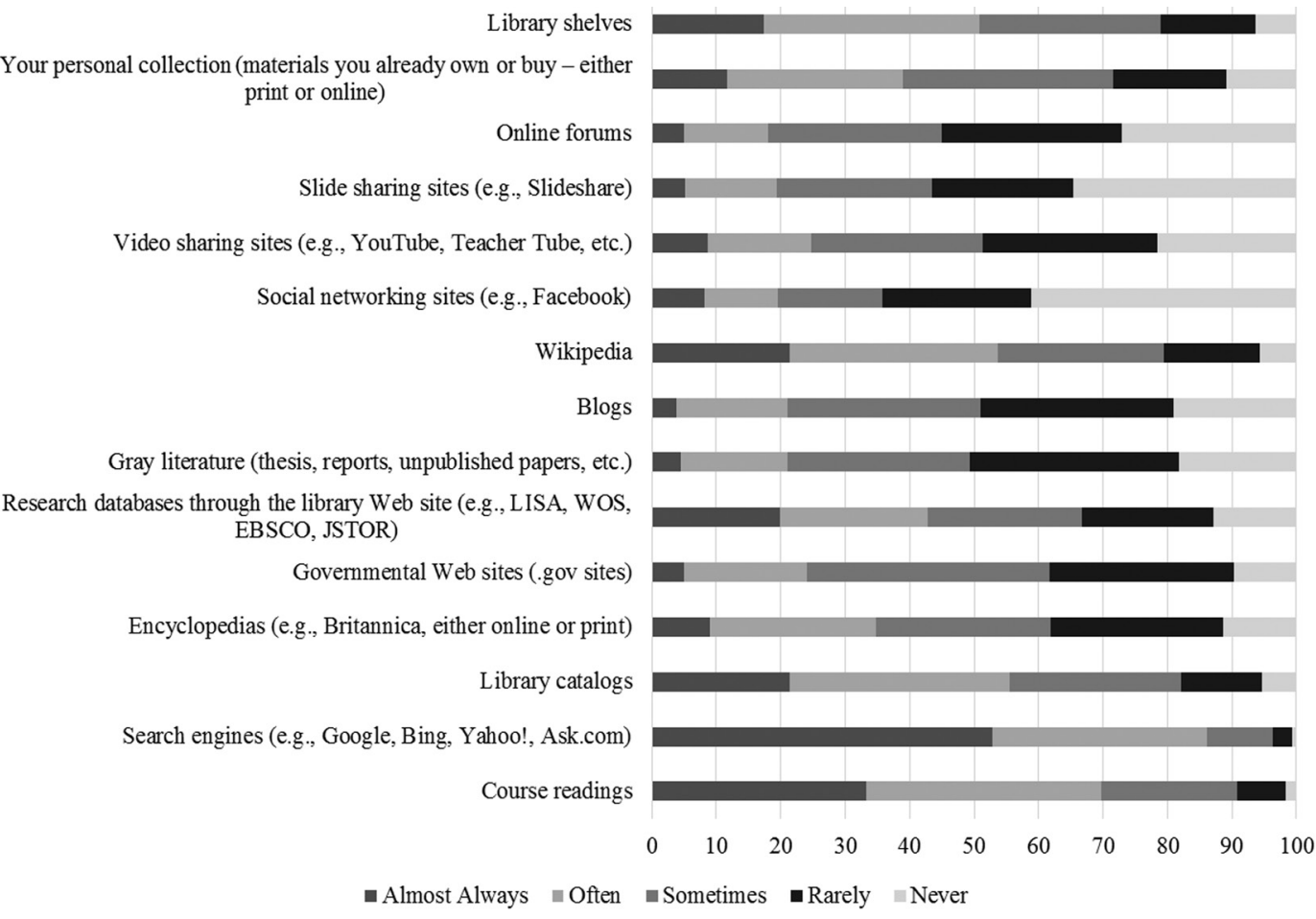

Figure 3. Frequency with which Students Report Consulting Resources, Aggregate Responses.

United States (34\%) and France (35\%) are least likely to consult library shelves. Students in Bulgaria (61\%) and Poland $(59 \%)$ are more likely to use a personal collection. Wikipedia is used most often by LIS students in France (86\% almost always or often use Wikipedia), followed by students in Poland (64\%) and Bulgaria $(63 \%)$, and used least often by students in Australia (14\%) and the United States
(21\%). Students in Australia are most likely to use library catalogs (94\%) and online forums $(35 \%)$, while students in the United States (93\%), Australia (90\%) and Singapore $(85 \%)$ report the highest usage of research databases. Course readings are heavily consulted by all students, but are most consulted by students in the United States $(90 \%)$ and least by students in Poland (44\%) and Turkey (51\%). Likewise,

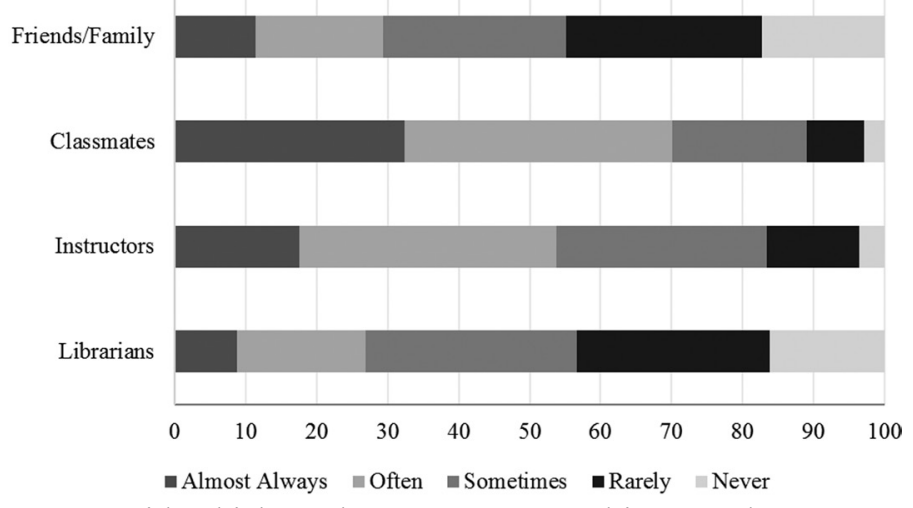

Figure 4. Frequency with which Students Report Consulting People, Aggregate Responses. 
the frequency with which LIS students consult people-instructors, classmates, librarians, and friends or family-is correlated by country $(p<0.05)$. All LIS students report consulting classmates first, except in the United States and Australia where instructors are consulted at higher rates. Students in Bulgaria (55\%) and Croatia $(45 \%)$ are the most likely to consult with a librarian, while students in Singapore $(12 \%)$ and Poland (14\%) are the least likely to do so. French students consult friends/family at the highest rates (54\%). Figure 5 shows the percentage at which students often or almost always consult certain people by country.

\section{Evaluating Resources}

Two questions focused on the criteria students use to evaluate resources they've found either through the library or on the Web. With regard to sources discovered through the library, students are not concerned with who published the information, or whether a librarian ever recommended the source to them. The most important criterion seems to be whether the resource is written in the student's native language, with $71 \%$ reporting that they "almost always" or "often" consider that criterion. Students are also concerned with how current the source is $(67 \%)$, and whether an instructor mentioned the source $(67 \%)$. The results concerning how students evaluate Web resources were more mixed, with students considering a wider range of criteria (such as domain name, site design, presence of a bibliography, and number of external links) more often. However, the criteria ranked most important were currency $(69 \%)$, whether the site was written in the student's native language $(66 \%)$, and whether an instructor had mentioned the site $(65 \%)$. Students were least interested in whether a librarian had recommended a Web site, with only $33 \%$ claiming they "almost always" or "often" consider this factor.

\section{Discussion}

The results of this study show that there are some patterns of information literacy

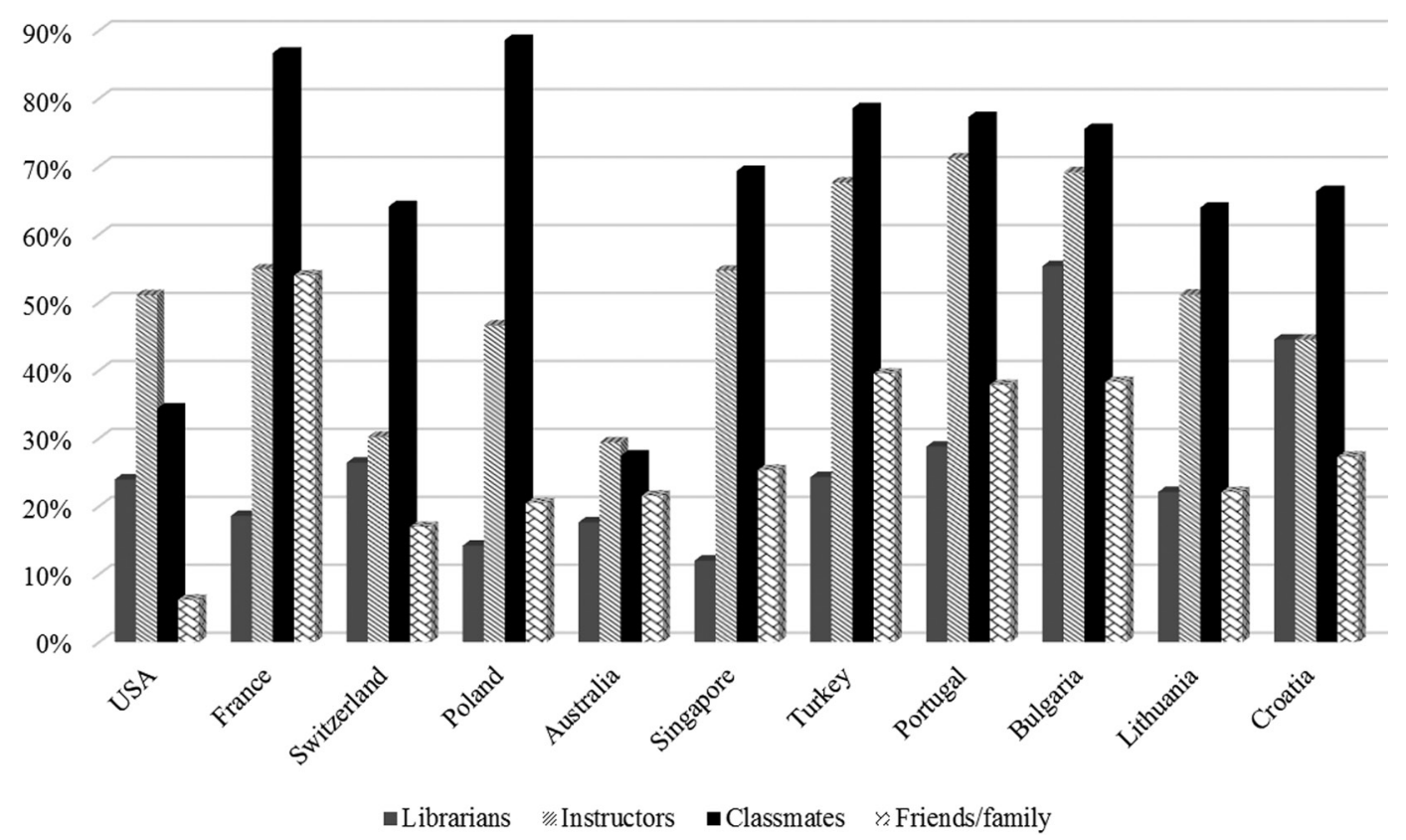

Figure 5. Frequency with which Students Report Consulting People by Country. 
levels and behavior common to LIS students in general, but that there are also some significant differences in the ways in which LIS students from different countries find and use information for courserelated assignments. Both the general patterns of behavior and the cross-country differences have implications for LIS faculty as they prepare their students to take on professional roles.

LIS students seem to be comfortable with developing search strategies, choosing search terms, and finding resources in libraries and on the Web. This finding is reassuring since search and location are still core areas for many librarians as they help patrons find resources and facilitate the development of their own search skills. Of course, this study relied solely on students' perceptions and self-reporting of their abilities. While we might expect that LIS students, especially those who might be further along in their program of study, would be effective searchers, this study cannot determine their actual abilities. In fact, other studies have demonstrated that the majority of online searchers enter only one or two search terms per query, and most either do not use Boolean logic at all, or use it incorrectly (Bernard \& Spink, 2006; Brusilovsky, Ahn, \& Rasumussen, 2010; Jansen \& Pooch, 2001; Lau \& Goh, 2006; Yu \& Young, 2004). Graduate students often are uncomfortable using or are unfamiliar with advanced search strategies (Catalano, 2013), and most students find choosing keywords and refining searches to be one of the most difficult aspects of information-seeking (Hoffman, Antwi-Nsiah, Feng, \& Stanley, 2008). According to Vezzosi (2009) even doctoral students are not necessarily adept at searching online databases, and rarely take the time to learn advanced search strategies, although when they do learn them they often acknowledge them to be time-savers. A future study might examine LIS student search behaviors directly to determine whether they use more sophisticated strategies and/ or are more efficient and effective in their searches than other populations. In the meantime, it is important for LIS educators to consider the extent to which they are teaching and assessing good search behaviors in their courses.

While literature reviews and other assignments require searching, instructors typically only see the end result in the form of a bibliography. They can assess from the bibliography whether students are finding relevant and authoritative sources, but they cannot necessarily judge whether the searches used to locate the materials were efficient or effective. Bawden (2007) underscores the importance of search for LIS students, contending that they must be experts at retrieving information, knowing how information is classified and indexed, understanding how retrieval systems are structured, and using sophisticated search strategies to make effective use of information sources and retrieval systems. He further argues that information retrieval and information seeking should form the core curriculum of LIS programs. To that end, faculty members might consider using exercises to practice search techniques, or asking students to outline their search process along with papers in order to determine whether students' confidence in searching is justified, and that they actually are performing high impact searches.

In fact, an analysis of the sources students use suggests that they are not all using resources that would require or even allow for sophisticated searching. For instance, course readings are among the most highly consulted resources. While resources selected and vetted by instructors might be a good starting point for research, Campello and Abreu (2005) note that if instructors provide the bulk of the material that students use in assignments, those students get less practice in the essential process of search and discovery. When students do go beyond course readings, there is significant variance by country with regard to resources used. All students report relying heavily on search engines, but students in France, Bulgaria, 
Turkey, Portugal, and Poland report much higher uses of Wikipedia, while students in the United States, Australia, and Singapore are much more likely to report using research databases and database providers like LISA and EBSCO. Nearly a third or more of students in France, Lithuania, Turkey, and Bulgaria indicated that deciding which database to use and finding articles in a database is difficult.

It is possible that students in some programs have not been exposed to, or perhaps have not had access to, some of the research databases which LIS students in other countries use regularly. On the other hand, it is possible that like most other populations, LIS students are relying on Google and Wikipedia because they are familiar and convenient resources. Understanding the structure of databases and being able to search them effectively is a crucial expectation of professional librarians. If students do not go beyond search engines or Wikipedia - the same resources the general public uses regularly - they will not be able to add value to their patrons' searches. As such, LIS faculty in all programs must incorporate use of databases into their courses and programs and find ways to ensure that students are using them. At the same time, faculty members will need to be aware that some students might have less experience with research databases and will need to offer additional support to those students.

There were several important areas where students from certain countries expressed greater levels of difficulty. Specifically, more than one-third of students in Turkey, Bulgaria, Croatia, Lithuania, Singapore, France, and Portugal express difficulty in evaluating Web sources. As professional librarians, however, these students will be expected to guide their patrons in the selection and evaluation of Web (and other) resources for research and decision-making. School and academic librarians will also be expected to provide instruction on evaluation to students. Indeed, in the United States, in- struction in evaluating Web sites is often begun in elementary school, which might reflect the relative confidence in their abilities that American students in this study express. Nevertheless, this confidence is self-reported and may not be completely reliable. LIS faculty should ensure that all library students build up the confidence and skills to quickly and accurately evaluate Web resources. LIS faculty working with students from countries that have expressed greater difficulty with such evaluation must be careful not to make assumptions about students' previous exposure to source evaluation. Faculty might do pretests, use clickers, or poll their classes to get a sense of student abilities and understanding of source evaluation, and provide extra guidance as needed. Faculty members might incorporate Web evaluation exercises into their courses. Reference, Information Sources and Services, and Information Literacy courses, are a natural fit for such topics as most of these courses devote substantial time to the evaluation of sources generally. Traditionally, however, these courses have often focused on examining sources by type: almanacs, encyclopedias, indexes, and so on. Given the lack of confidence some students feel, it might behoove faculty in these courses to spend more time on Web sources as a whole, with attention to concepts like authority which must be understood differently when evaluating online sources like Wikipedia or other social media.

Plagiarism and source citation was another area of concern for many survey respondents. Understanding what constitutes plagiarism and when and how to properly cite sources is crucial for librarians and library students. These findings confirm other studies that have demonstrated cross-cultural differences in the understanding and application of plagiarism practices (Amsberry, 2010; Sutton, Tayler, \& Johnston, 2014). Library students have an ethical obligation to abide by copyright and intellectual property laws. Further, the need to understand plagiarism 
extends beyond the student to a librarian's role as a professional. Many librarians will be called upon to assist patrons with questions in these areas. Many professional librarians become default copyright consultants, offering guidance to patrons on proper use of sources, delivering instruction on copyright, managing copyright requests, and sometimes even setting local policy. As such, it is important that library students are firmly grounded in how to avoid plagiarism, as well as in related areas of copyright law and proper citation of sources. But to what extent do LIS faculty explicitly teach these concepts, and to what extent do they assume students already know them? This study suggests that faculty might need to put more emphasis on plagiarism and citation.

It is interesting to note that in some cases LIS students engage in behaviors and attitudes very similar to other populations, including the undergraduates that served as the base for the original PIL study. For instance, the LIS students in this study generally find getting started on course assignments, and particularly defining and narrowing a topic, to be difficult. These are the same areas that Head (2007) and Head and Eisenberg (2009) found to be most difficult for undergraduates. This finding is especially noteworthy because academic and school librarians often assist students in the processes of gathering context and narrowing and defining a topic, so one might assume that LIS students would have learned (or be learning) techniques that could apply to their own coursework. Perhaps LIS faculty assume that students already understand how to engage in these processes. These findings suggest that, given students' levels of frustration, more time and explicit instruction need to be spent on context-gathering, both to support their own research and to help patrons in future professional practice.

Similarly, it is interesting that although LIS students would, presumably, have a better understanding of the ways in which librarians could help them with tasks from defining a topic to finding and evaluating resources, the students in this study still only turn to librarians for help as a last resort. Like students in other studies (Catalano, 2013; Head 2007; Head \& Eisenberg, 2009 ) they tend instead to rely on their professors. However, students in this study do seem more likely overall to consult library catalogs and library shelves than other searchers. There may not be a real role for LIS faculty to play here, besides perhaps encouraging students to consult with librarians or even directly pointing students to librarians when they come to their instructors with questions related to defining a topic or locating and evaluating sources. The finding does raise some questions, though, as to why even LIS students do not ask librarians for help. Do they feel like it is "cheating" to ask for help on library school assignments? Are instructors discouraging students from consulting with librarians, so that the instructor can better assess the students' skills? Are students embarrassed to ask for assistance, and feel they should be able to accomplish these tasks on their own? Perhaps the reason has more to do with the preference for convenience highlighted by Connaway, Dickey, and Radford (2011) and Connaway, Lanclos, and Bell (2013). Perhaps even students who presumably understand the value that librarians can bring to an information search find it too time-consuming or inconvenient to have meet with a librarian, and thus prefer to rely on what they can find on their own. However, the types of resources students report difficulty using; the difficulties some students express at finding context; the troubles with defining and narrowing a topic, and evaluating Web sources; suggests that they would benefit from the support of a librarian. In fact, this finding might have more implications for academic librarians than for LIS faculty. Perhaps they need to do more to reach out to students or find ways to make their services more accessible, whether that means more remote services, self-help resources, or a greater presence in student 
spaces. Perhaps LIS faculty and academic librarians need to work together more closely to ensure that referrals are being made when appropriate.

\section{Conclusion}

This study shows that LIS students display at least some of the same informationseeking behaviors and attitudes as other populations. They are confident in their overall searching abilities, but they have a hard time getting started on research assignments, including defining and narrowing down topics. They rely heavily on search engines, and express some concern about their ability to evaluate Web sources. They also report concern with determining what constitutes plagiarism and knowing when to cite sources. While these behaviors and attitudes are understandable, they raise some concerns as to whether LIS students are moving beyond the general population in their location, search, evaluation, and use of resources and building up the information literacy skills necessary to add value to their patrons' seeking and searching as professional librarians. These findings have implications for LIS faculty, who must decide whether their students are achieving the necessary level of mastery in these areas. Faculty will need to set clear goals for learning and assess student progress toward those goals, whether through assignments, tests, discussions, or other measures. Further, faculty will need to consider which areas must be addressed explicitly within the curriculum. For instance, faculty might not directly teach the specifics of plagiarism and citation, although they will have assignments that incorporate these skills. The results of this study suggest that, at least in some countries, students might need more explicit instruction in how to avoid plagiarism.

This study also found some significant differences in behaviors of students from different countries. Those specific findings will speak to LIS faculty in those countries, but they should also serve as a reminder to any LIS faculty who work with students from abroad that those students come to the program with different backgrounds and experiences. Faculty members need to be aware of and attuned to those differences, and be prepared to offer support to those students whose information literacy skills and behaviors or background knowledge may not conform to local expectations.

\section{References}

Amsberry, D. (2010). Deconstructing plagiarism: International students and textual borrowing practices. The Reference Librarian, 51(1), 31-44. doi: 10.1080/02763870903362183

Bawden, D. (2007). Information seeking and information retrieval: The core of the information curriculum? Journal of Education for Library and Information Science, 48(2), 125-138

Bernard, J. J., \& Spink, A. (2006). How are we searching the World Wide Web? A comparison of nine search engine transaction logs. Information Processing \& Management, 42(1), 248-63.

Brewerton, A. (2012). Re-skilling for research: Investigating the needs of researchers and how library staff can best support them. New Review of Academic Librarianship, 18(1), 96-110. doi: 10.1080/13614533.2012.665718

Brown, C. M, \& Ortega, L. (2005). Informationseeking behavior of physical science librarians: Does research inform practice? College \& Research Libraries, 66(3), 231-247.

Brusilovsky, P., Ahn, J., and Rasmussen, E. (2010). Teaching information retrieval with web-based interactive visualization. Journal of Education for Library and Information Science, 51(3), 187200.

Campello, B., \& Abreu, V. L. F. G. (2005). Information literacy and the education of school librarians. School Libraries Worldwide, 11(1), 37-52.

Catalano, A. (2013). Patterns of graduate students' information seeking behavior: A meta-synthesis of the literature. Journal of Documentation, 69(2), 243-274. doi: 10.1108/00220411311300066

Chung, J. S., \& Neuman, D. (2007). High school students' information seeking and use for class projects. Journal of the American Society for Information Science \& Technology, 58(10), 15031517. doi: 10.1002/asi.20637

Connaway, L. S., Lanclos, D. M., \& Hood, E. M. (2013, December 6). I always stick with the first thing that comes up on Google ... Where peo- 
ple go for information, what they use, and why. EDUCAUSE Review Online. Retrieved from $\mathrm{http} / / / \mathrm{www}$.educause.edu/ero/article/i-alwaysstick-first-thing-comes-google-where-people-goinformation-what-they-use-and-why

Connaway, L. S., Dickey, T. J., \& Radford, M. L. (2011). "If it is too inconvenient I'm not going after it:" Convenience as a critical factor in information-seeking behaviors. Library and Information Science Research, 33(3), 179-190.

Conway, K. (2011). How prepared are students for post-graduate study? A comparison of the information literacy skills of commencing undergraduate and post-graduate information studies students at Curtin University. Australian Academic \& Research Libraries, 42(2), 121-135. doi: 10.1080/00048623.2011.10722218

de Jong, C., \& Branch, J. L. (2006). How are teacher-librarians finding resources for coursework? Distance learners and the role of university library services. Journal of Library \& Information Services for Distance Learning, 2(3), 63-74. doi:10.1300/J192v02n03 06

Estabrook, L., Witt, E., \& Rainie, L. (2007). Information Searches that Solve Problems. Washington D.C.: Pew Research Center's Internet \& American Life Project. Retrieved from http:// www.pewinternet.org/files/old-media//Files/Reports/2007/Pew_UI_LibrariesReport.pdf.pdf

Fisher, K. E., Erdelez, S., \& McKechnie, L. (Eds.). (2005). Theories of Information Behavior. Medford, NJ: Information Today.

Fox, S. (2010). Health sites: Some are more equal than others. Pew Research Center's Internet \& American Life Project. Retrieved from http:// www.pewinternet.org/2010/01/21/health-sitessome-are-more-equal-than-others/

Gauder, B. (Ed). (2010). Perceptions of libraries, 2010: Context and communities. Ohio: OCLC.

Head, A. J. (2007). Beyond Google: How do students conduct academic research? First Monday, 12(8).

Head, A. J., \& Eisenberg, M. B. (2009). Lessons learned: How college students seek information in the digital Age. Washington: The University of Washington.

Hoffman, K., Antwi-Nsiah, F., Feng, V., \& Stanley, M. (2008). Library research skills: A needs assessment for graduate student workshops. ISsues in Science \& Technology Librarianship, 53, $1-13$.

Jansen, B. J., \& Pooch, U. (2001). A review of web searching studies and a framework for future research. Journal of the American Society for Information Science \& Technology, 52(3), 235-246.

Korobili, S., Malliari, A., \& Zapounidou, S. (2011). Factors that influence information-seeking be- havior: The case of Greek graduate students. The Journal of Academic Librarianship, 37(2), 155-165

Kurbanoglu, S. (2003). Self-efficacy: A concept closely linked to information literacy and lifelong learning. Journal of Documentation, 59(6), 635-646. http://dx.doi. org/10.1108/00220410310506295

Lau, E. P., \& Goh, D. H. (2006). In search of query patterns: A case study of a university OPAC. Information Processing \& Management, 42(5), 1316-1329.

Malliari, A., Korobili, S., \& Togia, A. (2012). IT self-efficacy and computer competence of LIS students. Electronic Library, 30(5), 608-622. http://dx.doi.org/10.1108/02640471211275675

O'Farrell, M. \& Bates, J. (2009). Student information behaviours during group projects: A study of LIS students in University College Dublin, Ireland. Aslib Proceedings, 61(3), 302-315. doi: 10.1108/00012530910959835

Okello-Obura, C., \& Ikoja-Odongo, J. R. (2010). Electronic information seeking among LIS postgraduate students at Makerere University, Uganda. Library Philosophy and Practice.

Purcell, K., Brenner, J., \& Rainie, L. (2012). Search engine use 2012. Washington D.C.: Pew Research Center's Internet \& American Life Project.

Purcell K., Rainie L., Heaps A., Buchanan J., Friedrich L., Jacklin A., . . . Zickuhr K. (2012). How teens do research in the digital world. Washington D.C.: Pew Research Center's Internet \& American Life Project.

Sutton, A., Taylor, D., \& Johnston, C. (2014). A model for exploring student understandings of plagiarism. The Journal of Further and Higher Education, 38(1), 129-146. doi: 10.1080/0309877X.2012.706807

Tan, S., Gorman, G., \& Singh, D. (2012). Information literacy competencies among school librarians in Malaysia. LIBRI: International Journal of Libraries and Information Services, 62(1), 98-107. doi: 10.1515/libri-2012-0007

Tracy, D. G., \& Searing, S. E. (2014). LIS graduate students as library users: A survey study. The Journal of Academic Librarianship, 40(3-4), 367-378. doi: 10.1016/j.acalib.2014.05.004

Vezzosi, M. (2009). Doctoral students' information behavior: An exploratory study at the University of Parma (Italy). New Library World, 110(1/2), 65-80. http://dx.doi. org/10.1108/03074800910928595

Yu, H., \& Young, M. (2004). The impact of web search engines on subject searching in OPAC. Information Technology \& Libraries, 23(4), 168-180. 


\section{Appendix A: Perceived Level of Difficulty with Assignments by Country}

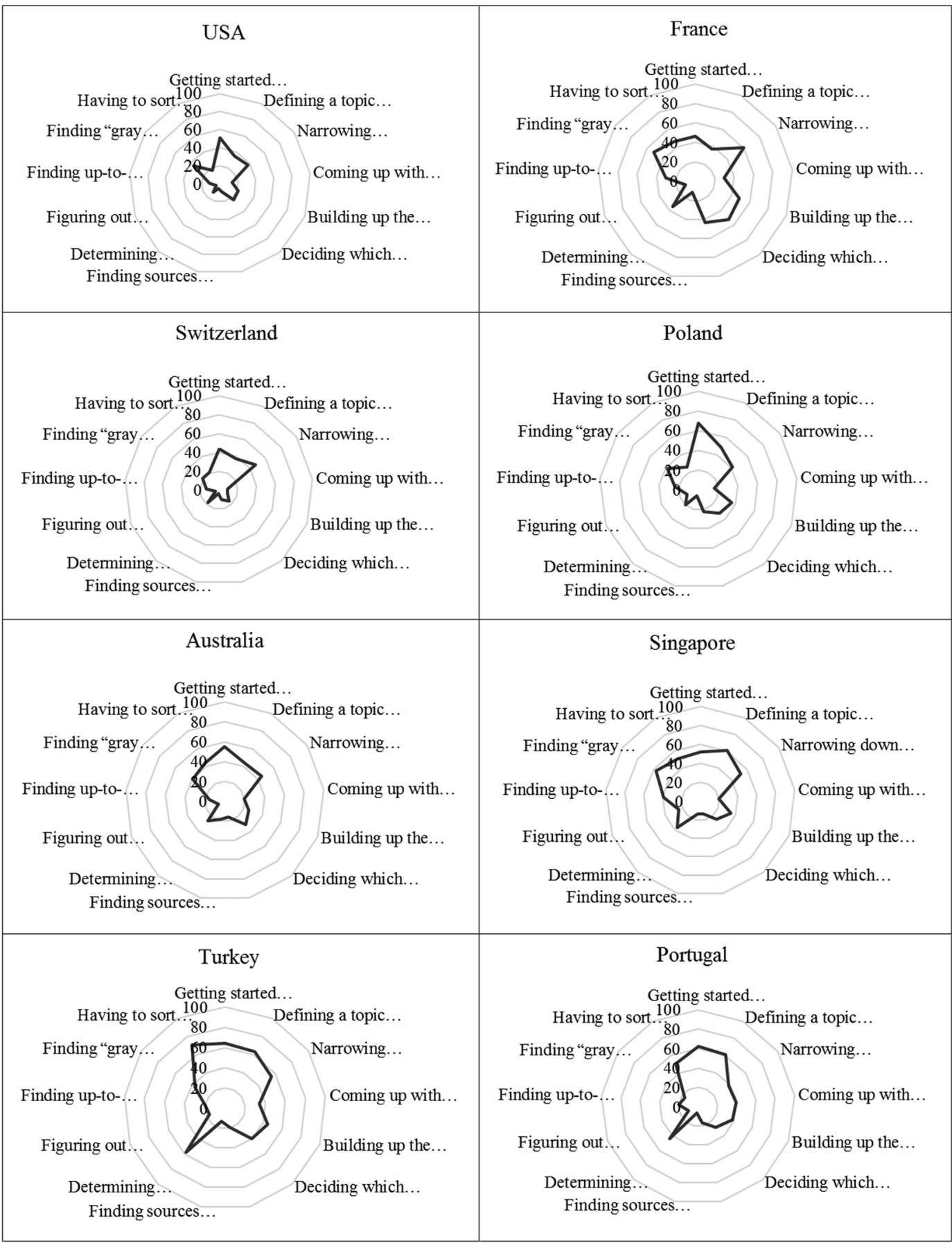




\begin{tabular}{|c|c|}
\hline & Bulgaria \\
Finding up-to-...
\end{tabular}

Category labels from top:

Getting started on the assignment is difficult

Defining a topic for the assignment is difficult

Narrowing down a topic is difficult

Coming up with search terms is difficult

Building up the search strategy is difficult

Deciding which database to use is difficult

Finding articles in the library's databases is difficult

Finding sources to use "out on the web" is difficult

Determining whether a Web site is credible or not is difficult

Figuring out where to find sources in the library is difficult

Finding up-to-date materials is difficult

Finding "gray literature" (e.g. thesis, reports, unpublished papers, etc.) is difficult

Having to sort through all the irrelevant results that I get to find what I need is difficult 


\section{Appendix B: Perceived Level of Difficulty in Preparing Assignments by Country}

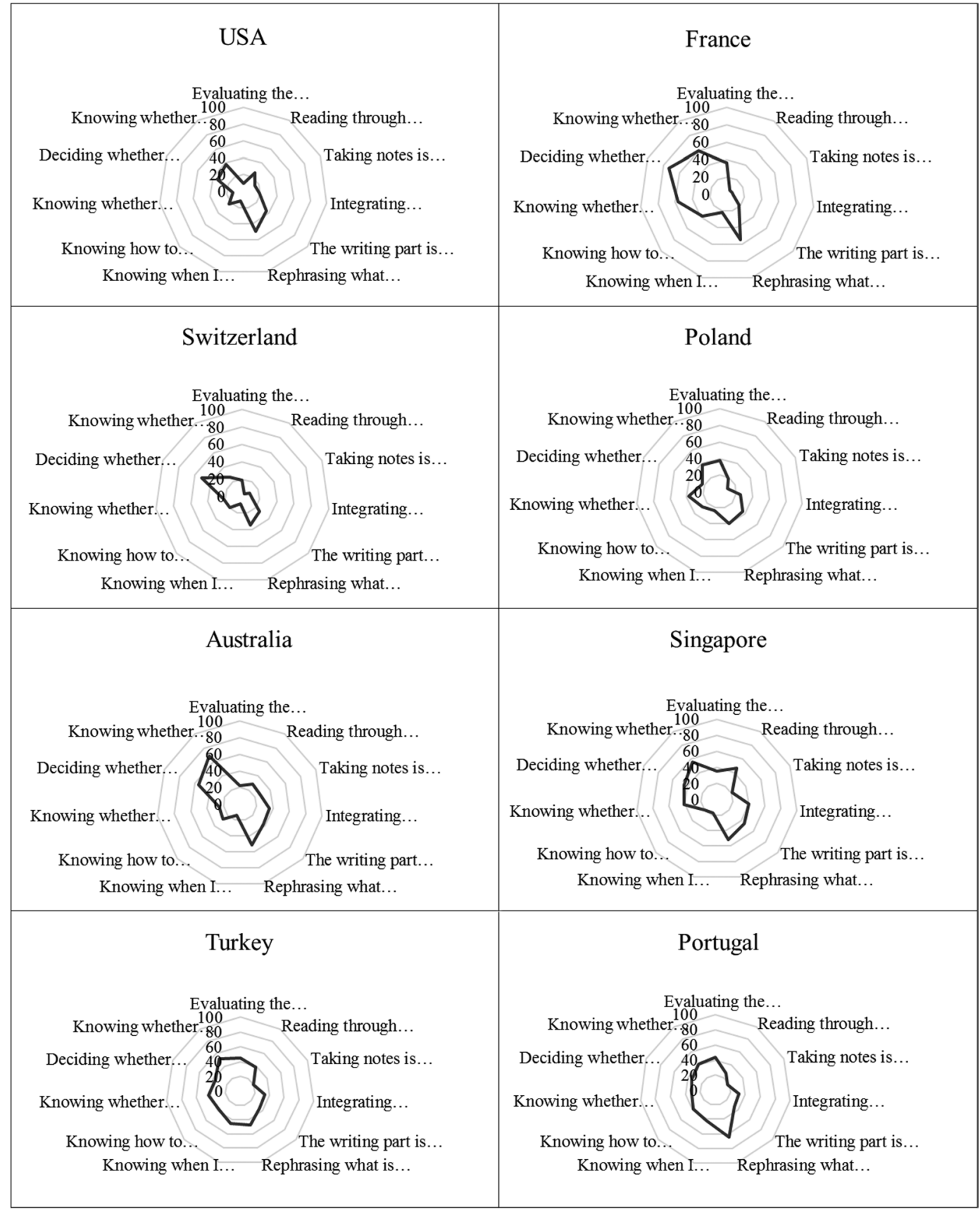




\begin{tabular}{|c|c|}
\hline \multicolumn{2}{|c|}{ Bulgaria } \\
Knowing whether...
\end{tabular}

Category labels from top:

Evaluating the sources I've found is difficult

Reading through the material is difficult

Taking notes is difficult

Integrating different sources from my research into my assignment is difficult

The writing part is difficult

Re-phrasing what is already well-expressed in a source is difficult

Knowing when I should cite a source is difficult

Knowing how to cite a source in the right format is difficult

Knowing whether my use of a source, in certain circumstances, constitutes plagiarism or not is difficult

Deciding whether "I'm done" or not is difficult

Knowing whether I've done a good job on the assignment or not is difficult 